INTIQAD: JURNAL AGAMA DAN PENDIDIKAN ISLAM

ISSN 1979-9950 (print) || ISSN 2598-0033 (online), http://jurnal.umsu.ac.id/index.php/intiqad DOI: $10.30596 /$ intiqad.v\%vi\%i.3753

Vol. 11, No. 2 (Desember 2019)

\title{
Metode Pembelajaran Al-Islam Dan Kemuhammadiyahan Di Universitas Muhammadiyah Sumatera Utara
}

\author{
Rasta Kurniawati Br. Pinem \\ Universitas Muhammadiyah Sumatera Utara \\ email: rastakurniawati@umsu.ac.id
}

\begin{abstract}
Some problems that faced by the students in University of Muhammadiyah Sumatera Utara are have not disciplined in carrying out worship, have not well behaved in conveying their aspirations, some have not dressed in accordance with Islamic law, and there are only few alumni who become Muhammadiyah cadres whom automatically expected to be active in Muhammadiyah organization. There are several factors for these situation, including the learning method practiced by Al-Islam and Kemuhammadiyahan Lecturers (AIK) seemed monotonous and less interesting then the students feel bored to attend AIK lectures. The purpose of the study is to provide a learning method that fun and creative for AIK lecturers. In specific, the objective of the study is to detect and analyze the learning methods that have been applied by AIK lecturers in UMSU. The result after the observation has done, it was found that there were several learning methods practiced by AIK lecturers. All methods can be classified into three categories, classical, middle and modern methods.
\end{abstract}

Keywords: Method, Learning, Al-Islam and

Kemuhammadiyahan System, Globalization.

\begin{tabular}{l}
\hline Abstrak \\
\hline Beberapa permasalahan mahasiswa di Universitas \\
Muhammadiyah Sumatera Utara adalah belum tertib dalam \\
menjalankan Ibadah, belum sepenuhnya berakhlak dalam \\
menyampaikan aspirasi, ada yang belum berpakaian yang \\
sesuai dengan syariat Islam, dan masih sedikit alumni \\
UMSU yang menjadi kader Muhammadiyah yang otomatis \\
diharapkan aktif di persyarikatan Muhammadiyah. \\
Beberapa faktor yang menyebabkan fenomena ini, \\
diantaranya karena metode pembelajaran yang dipraktekkan \\
Dosen Al-Islam dan Kemuhammadiyahan (AIK) terkesan \\
monoton dan kurang menarik dalam menyampaikan materi \\
pembelajaran. Sehingga mahasiswa merasa bosan untuk \\
mengikuti perkuliahan AIK. \\
Tujuan penelitian ini adalah untuk memberikan sebuah
\end{tabular}

Artikel Info

Received:

21 Agustus 2019

Revised:

21 Oktober 2019

Accepted:

23 November 2019

Published:

04 Desember 2019 
tawaran metode pembelajaran yang kreatif dan menyenangkan bagi dosen AIK. Secara khusus target yang ingin dicapai dari penelitian ini adalah untuk mendeteksi/menganalisa metode pembelajaran yang selama ini dipraktekkan oleh dosen AIK di UMSU.

Setelah observasi ditemukan ada beberapa metode pembelajaran yang diperaktekkan oleh dosen AIK di UMSU dalam perkuliahan. Dari kesemua metode yang ditemukan itu dapat dikelompokkan menjadai tiga katagori yaitu metode klasik, pertengahan dan modern.

\section{Kata Kunci : Metode, Pembelajaran, Al-Islam dan} Kemuhammadiyahan

\section{A. Pendahuluan}

Salah satu universitas Islam yang ada di Sumatera Utara adalah Universitas Muhammadiyah Sumatera (UMSU). Sebagai Universitas Islam, UMSU memiliki tekad untuk mengembangkan dan menjaga nilai-nilai Islam agar tetap menjadi budaya di masyarakat. Salah satu cara yang dilakukan UMSU dalam membudayakan nilai-nilai Islam adalah dengan membekali para mahasiswa di semua Fakultas dengan muatan-muatan keIslaman yang diterapkan dalam mata kuliah al-Islam dan Kemuhammadiyahan.

Mata kuliah Al-Islam yang dimaksudkan terdiri dari Aqidah-Akhlak diberikan pada semester I, Ibadah diberikan pada semester II, Muamalah diberikan pada semester III dan
Kemuhammadiyahan diberikan pada semester IV.

$$
\text { UMSU berharap dengan }
$$

banyaknya jumlah matakuliah keislaman yang diberikan, mahasiswa memiliki pribadi-pribadi Islam dan mengamalkan nilai-nilai Islam dalam kehidupan seharihari. Seperti tertib Ibadah, berakhlak mulia dan menjadi muslim yang tangguh serta bersedia dengan sukarela bergabung dengan organisasi Muhammadiyah dalam mendakwahkan Islam di masyarakat.

Dosen mata kuliah Al-Islam dan Kemuhammadiyahan memiliki peranan yang besar dalam mewujudkan visi dan misi UMSU. Oleh sebab itu dosen diharapkan mampu mengemas metode pembelajaran di kelas sesuai dengan perkembangan kurikulum pendidikan yang bertujuan supaya 
ISSN 1979-9950 (print) || ISSN 2598-0033 (online), http://jurnal.umsu.ac.id/index.php/intiqad

DOI: $10.30596 /$ intiqad.v\%vi\%i.3753

Vol. 11, No. 2 (Desember 2019)

alumni Perguruan Tinggi dapat menjadi pribadi yang bertaqwa.

Berdasarkan pengamatan awal terhadap mahasiswa ditemukan sebagian mahasiswa yang belum tertib dalam menjalankan Ibadah, menyampaikan aspirasi belum sesuai dengan bahasa yang santun, berpakaian yang belum sesuai dengan syariat Islam, dan masih sedikit alumni UMSU yang aktif di persyarikatan Muhammadiyah.

Dari hasil diskusi kecil dengan beberapa orang mahasiswa, ditemukan beberapa faktor yang menyebabkan fenomena ini bisa terjadi, diantaranya karena metode pembelajaran yang dipraktekkan Dosen Al-Islam dan Kemuhammadiyahan terkesan monoton dan kurang menarik. Sehingga mahasiswa merasa bosan untuk mengikuti perkuliahan Studi Islam dan Kemuhammadiyahan. Oleh sebab itu kami tertarik untuk melihat lebih dalam dengan melakukan kajian "Metode Pembelajaran Dosen Al-Islam dan Kemuhammadiyahan di Universitas Muhammadiyah Sumatera Utara"

\section{Tinjauan Pustaka}

\section{Pengertian Metode Pembelajaran}

Metode Pembelajaran terdiri dari dua kata, yaitu metode dan pembelajaran. Metode secara harfiah berarti 'cara'. Dalam pemakaian umum adalah suatu cara atau prosedur yang dipakai untuk mencapai suatu tujuan. Dalam kamus ilmiah popular disebutkan bahwa metode adalah cara yang teratur dan sistematis untuk pelaksanaan sesuatu. ${ }^{1}$

Oemar Hamalik mengatakan triktrik pembelajaran yang dilakukan oleh dosen mempengaruhi berhasil atau tidaknya mahasiswa dalam memahami materi pembelajaran ${ }^{2}$.

Pembelajaran adalah istilah kualitatif yang dipakai untuk mengajar. Secara sederhana mengajar adalah suatu rangkaian kegiatan penyampaian bahan pelajaran kepada murid agar dapat menerima, menanggapi, menguasai dan mengembangkan bahan pelajaran itu.

Menurut Oemar Hamalik "pembelajaran adalah suatu kombinasi yang tersusun meliputi unsur-unsur manusiawi, material, fasilitas, perlengkapan dan prosedur yang saling

${ }^{1}$ Pius A. Partanto dan M.Dahlan Al-Barry, Komunikasi Organisasi; Strategi Meningkatkan Kinerja Perusahaan, (edt. Deddy Mulyana), (Bandung: Rosda Karya, 1994), h. 461.

${ }^{2}$ Oemar Hamalik, Proses Belajar Pembelajaran, (Jakarta : Bumi Aksara, 2001), h. 461 
INTIQAD: JURNAL AGAMA DAN PENDIDIKAN ISLAM

ISSN 1979-9950 (print) || ISSN 2598-0033 (online), http://jurnal.umsu.ac.id/index.php/intiqad

DOI: $10.30596 /$ intiqad.v\%vi\%i.3753

Vol. 11, No. 2 (Desember 2019)

mempengaruhi mencapai tujuan

pembelajaran"3

Pembelajaran

berarti

membelajarkan, dosen memiliki fungsi sebagai orang yang mampu mengemas materi kuliah dengan sedemikian rupa, metode tertentu sehingga mahasiswa bisa belajar dengan efektif.

Fungsi dosen adalah sebagai motivator agar mahasiswa mampu belajar dengan baik. Jadi posisi dosen dan mahasiswa sama-sama sebagai orang yang aktif. Sehingga yang aktif dalam proses belajar itu tidak hanya dosen.

Jadi, metode pembelajaran adalah cara-cara menyajikan bahan pelajaran kepada mahasiswa untuk tercapainya tujuan yang telah ditetapkan. Adapun metodologi mengajar adalah ilmu yang mempelajari cara-cara menyampaikan materi kepada peserta didik, yang bertujuan agar tercapai tujuan pembelajaran. ${ }^{4}$
2. Peranan

Dosen

Dalam

\section{Aktivitas Pembelajaran}

Menurut hasil forum Carnegie tentang pendidikan, pada abad informs ini terdapat sejumlah kemampuan yang harus dimiliki oleh dosen sebagai tenaga pendidik dalam melakukan pembelajaran. Adapun kemampuan yang dimaksud adalah memiliki pemahaman yang baik tentang kerja, baik fisik, maupun sosial, memiliki rasa dan kemampuan mengumpulkan dan menganalisis data. Hal lain adalah mampu memahamkan mahasiswa, memiliki kemampuan mempercepat kreativitas sejati mahasiswa dan memiliki kemampuan kerjasama dengan orang lain.

Dosen diharapkan dapat belajar sepanjang hayat seirama dengan pengetahuan yang mereka perlukan untuk mendukung perkerjaannya serta menghadapi tantangan dan kemajuan sains dan teknologi. Dosen tidak diharuskan memiliki semua pengetahuan, tetapi hendaknya memiliki pengetahuan yang cukup sesuai dengan yang mereka perlukan, dimana

\footnotetext{
${ }^{3}$ Oemar Hamalik, Pembelajaran Efektif, (Jakarta: Bumi Aksara, 2008), h.57

${ }^{4}$ Adrian, Metodologi Pembelajaran Efektif, (Jakarta: Bumi Aksara, 2006), h.66.
} 
INTIQAD: JURNAL AGAMA DAN PENDIDIKAN ISLAM

ISSN 1979-9950 (print) || ISSN 2598-0033 (online), http://jurnal.umsu.ac.id/index.php/intiqad

DOI: $10.30596 /$ intiqad.v\%vi\%i.3753

Vol. 11, No. 2 (Desember 2019)

memperolehnya dan bagaimana memaknainya. ${ }^{5}$

Para dosen diharapkan bertindak atas dasar berpikir yang mendalam, bertindak independen dan kolaboratif satu sama lain dan siap mengembangkan pertimbangan-pertimbangan kritis, penguasaaan materi, dosen juga dituntut memiliki keragaman model atau metode dalam pembelajaran, karena tidak ada satu metode pembelajaran yang dapat digunakan untuk mencapai tujuan belajar dari materi kuliah yang beragam.

Apabila konsep pembelajaran tersebut dipahami oleh para dosen, khususnya dosen Al-Islam dan Kemuhammadiyahan, maka upaya mendesain pembelajaran bukan menjadi beban, tetapi menjadi pekerjaan yang menantang. Konsep pembelajaran tersebut meletakkan landasan yang meyakinkan bahwa peranan dosen tidak lebih dari sebagai motivator dan fasilitator. Adapun fasilitator memiliki konsekuensi langsung sebagai perancang, model, pelatih dan pembimbing.

${ }^{5}$ Muhammad Ali, Dosen Dalam Proses Pembelajaran (Bandung: Sinar Baru Algesindo, 2007), h. 60.
Fasilitator berfungsi secara lebih spesifik, sebagai expert learners, sebagai manager dan mediator. Fungsi experet learners dosen diharapkan memiliki pemahaman mendalam tentang materi pembelajaran, menyediakan waktu yang cukup untuk mahasiswa, menyediakan masalah dan alternatif solusi, memonitor proses belajar dan pembelajaran, merubah metode pembelajaran ketika mahasiswa sulit mencapai tujuan, berusaha mencapai tujuan, kognitif, afektif dan psikomotor.

Fungsi manager, dosen berkewajiban memonitor hasil belajar pada mahasiswa dan masalah-masalah yang dihadapi mereka. Memonitor disiplin kelas dan hubungan interpersonal dan memonitor ketepatan penggunaan waktu dalam menyelesaikan tugas.

Fungsi mediator, dosen memandu menengahi antar mahasiswa, membantu memformulasikan pertanyaan atau mengkonstruksi representasi visual dari suatu masalah, memandu mengembangkan sikap positif terhadap belajar, pemusatan perhatian, mengaitkan informasi baru dengan pengetahuan awal dan menjelaskan serta mengaitkan gagasan para mahasiswa, 
ISSN 1979-9950 (print) || ISSN 2598-0033 (online), http://jurnal.umsu.ac.id/index.php/intiqad

DOI: $10.30596 /$ intiqad.v\%vi\%i.3753

Vol. 11, No. 2 (Desember 2019)

pemodelan proses berpikir dengan menunjukkan kepada mahasiswa ikut berpikir kritis.

\section{Ciri Pembelajaran Efektif}

Adapun ciri-ciri pembelajaran yang efektif adalah a. mahasiswa aktif mengobservasi, membandingkan, dan menemukan konsep. b. Dosen menyediakan materi sebagai fokus berpikir dan berinteraksi dalam pelajaran. c. Mahasiswa melakukan pengkajian. d. Dosen memberikan arahan dan tuntunan kepada mahasiswa dalam menganalisis yang mereka temukan. e. Fokus pembelajaran adalah penguasaan materi dan pengembangan keterampilan berpikir. f. Dosen menggunakan teknik mengajar yang bervariasi sesuai dengan materi perkuliahan. $^{6}$

\section{Metode-metode Pembelajaran}

Banyak sekali metode-metode pembelajaran yang bisa dipakai oleh seorang dosen dalam membelajarkan mahasiswa. Oleh sebab itu sebelum peneliti melihat metode apa saja yang selama ini dipakai oleh dosen-dosen AlIslam dan Kemuhammadiyahan dalam membelajarkan mahasiswanya, alangkah baiknya peneliti paparkan sedikti tentang metode pembelajaran yang ada dalam dunia pendidikan. Adapun metode pembelajaran menurut Suharsimi Arikunto $^{7}$ adalah sebagai berikut:

a) Koperatif (CL, Cooperative Learning), yaitu metode pembelajaran koperatif adalah kegiatan pembelajaran dengan cara berkelompok untuk bekerja sama saling membantu mengkontruksi

konsep, menyelesaikan persoalan, atau inkuiri.

b) Kontekstual (CTL, Contextual Teaching and Learning) Pembelajaran kontekstual adalah pembelajaran yang dimulai dengan sajian atau tanya jawab lisan (ramah, terbuka, negosiasi) yang terkait dengan dunia nyata kehidupan mahamahasiswa (daily life modeling).

c) Pembelajaran Langsung (DL, Direct Learning). Pengetahuan yang bersifat informasi dan

\footnotetext{
${ }^{7}$ Suharsimi Arikunto. Model-Model Metode Pembelajaran, (Makalah Seminar Nasional Pendidikan, 2008, di Universitas Negeri Medan).
}

\footnotetext{
${ }^{6}$ Oemar Hamalik,Op.Cit.,
} 
INTIQAD: JURNAL AGAMA DAN PENDIDIKAN ISLAM

ISSN 1979-9950 (print) || ISSN 2598-0033 (online), http://jurnal.umsu.ac.id/index.php/intiqad

DOI: $10.30596 /$ intiqad.v\%vi\%i.3753

Vol. 11, No. 2 (Desember 2019)

prosedural yang menjurus pada keterampilan dasar akan lebih efektif jika disampaikan dengan cara pembelajaran langsung.

d) Pembelajaran

Berbasis masalah (PBL, Problem Based

Learning). Model pembelajaran ini melatih dan mengembangkan kemampuan untuk menyelesaikan masalah yang berorientasi pada masalah yang otentik dari kehidupan aktual mahasiswa, untuk merangsang kemampuan berpikir mereka.

e) Problem Solving. Problem solving adalah mencari atau menemukan cara penyelesaian, yang akhirnya menemukan solusi. Seperti: mengidentifkasi, mengeksplorasi, menginvestigasi, menduga.

f) Problem Posing, yaitu pemecahan masalah dengan melalui elaborasi, yaitu merumuskan kembali masalah menjadi bagian-bagian yang lebih simple sehingga dipahami. Misalanya memahami, jalan keluar, identifikasi kekeliruan, cari alternative. g) Problem Terbuka (OE, Open

Ended), artinya pembelajaran yang menyajikan permasalahan dengan pemecahan berbagai cara (flexibility) dan solusinya juga bisa beragam (multi jawab, fluency). Metode ini melatih dan menumbuhkan orisinilitas ide, kreativitas, kognitif tinggi, kritis, komunikasi-interaksi, sharing, keterbukaan, dan sosialisasi. Mahasiswa dituntut untuk berimprovisasi mengembangkan metode, cara, atau pendekatan yang bervariasi dalam memperoleh jawaban, jawaban mahasiswa beragam. Selanjutnya mahasiswa juga diminta untuk menjelaskan proses mencapai jawaban tersebut. Dengan demikian model pembelajaran ini lebih mementingkan proses daripada produk yang akan membentuk pola pikir, keterpasuan, keterbukaan, dan ragam berpikir.

h) Probing-prompting. Teknik probing-prompting adalah pembelajaran dengan cara dosen menyajikan serangkaian pertanyaan yang sifatnya 
ISSN 1979-9950 (print) || ISSN 2598-0033 (online), http://jurnal.umsu.ac.id/index.php/intiqad

DOI: $10.30596 /$ intiqad.v\%vi\%i.3753

Vol. 11, No. 2 (Desember 2019)

menuntun dan menggali sehingga terjadi proses berpikir yang mengaitkan pengetahuan setiap mahasiswa dan pengalamannya dengan pengetahuan baru yang sedang dipelajari. Selanjutnya mahasiswa mengkonstruksi konsep-prinsip-aturan menjadi pengetahuan baru, dengan demikian pengetahuan baru tidak diberitahukan.

i) SAVI. Pembelajaran SAVI adalah pembelajaran yang menekankan bahwa belajar haruslah memanfaatkan semua alat indra yang dimiliki mahasiswa. Istilah SAVI sendiri adalah kependekan dari: Somatic yang bermakna gerakan tubuh (hands-on, aktivitas fisik) di mana belajar dengan mengalami dan melakukan; Auditory yang bermakna bahwa belajar haruslah dengan melalui mendengarkan, menyimak, berbicara, presentasi, argumentasi, mengemukakan pendapat, dan menanggapi ; Visualization yang bermakna belajar haruslah menggunakan indra mata melalui mengamati, menggambar, mendemonstrasikan, membaca, menggunakan media dan alat peraga; dan Intellectualy yang bermakna bahwa belajar haruslah menggunakan kemampuan berpikir (minds-on) belajar haruslah dengan konsentrasi pikiran dan berlatih menggunakannya melalui bernalar, menyelidiki, mengidentifikasi, menemukan, mencipta, mengkonstruksi, memecahkan masalah, dan menerapkan.

j) TAI (Team Assisted Individualy), yaitu Bantuan Individual dalam Kelompok (Bidak) dengan karateristirk tanggung jawab belajar ada pada mahasiswa. Oleh karena itu mahasiswa harus membangun pengetahuan tidak menerima apa adanya dari dosen. Misalnya dengan membuat kelompok heterogen dan berikan bahan ajar berupak modul, mahasiswa belajar kelompok dengan dibantu oleh mahasiswa yang mampu memimpin anggota kelompok secara individual, saling tukar jawaban, saling berbagi sehingga 
INTIQAD: JURNAL AGAMA DAN PENDIDIKAN ISLAM

ISSN 1979-9950 (print) || ISSN 2598-0033 (online), http://jurnal.umsu.ac.id/index.php/intiqad

DOI: $10.30596 /$ intiqad.v\%vi\%i.3753

Vol. 11, No. 2 (Desember 2019)

terjadi diskusi, penghargaan kelompok dan refleksi serta tes formatif.

k) NHT (Numbered Head Together) adalah salah satu tipe dari pembelajaran koperatif dengan membuat pengarahan, buat kelompok heterogen dan tiap mahasiswa memiliki nomor tertentu, berikan persoalan materi bahan ajar (untuk tiap kelompok sama tapi untuk tiap mahasiswa tidak sama sesuai dengan nomor mahasiswa, tiap mahasiswa dengan nomor sama mendapat tugas yang sama) kemudian bekerja kelompok, presentasi kelompok dengan nomor mahasiswa yang sama sesuai tugas masing-masing sehingga terjadi diskusi kelas, kuis individual dan buat skor perkembangan tiap mahasiswa, umumkan hasil kuis dan beri reward.

l) Jigsaw. Model pembelajaran ini termasuk pembelajaran koperatif dengan Pengarahan, informasi bahan ajar, buat kelompok heterogen, berikan bahan ajar yang terdiri dari beberapa bagian sesuai dengan banyak mahasiswa dalam kelompok, tiap anggota kelompok bertugas membahas bagian tertentu, tiap kelompok bahan belajar sama, buat kelompok ahli sesuai bagian bahan ajar yang sama sehingga terjadi kerja sama dan diskusi, kembali ke kelompok asal, pelaksanaan tutorial pada kelompok asal oleh anggota kelompok ahli, penyimpulan dan evaluasi, refleksi.

m) TPS (Think Pairs Share). Model pembelajaran ini tergolong tipe koperatif dengan cara dosen menyajikan materi klasikal, berikan persoalan kepada mahasiswa dan mahasiswa bekerja kelompok dengan cara berpasangan sebangku-sebangku (think-pairs), presentasi kelompok (share), kuis individual, buat skor perkembangan tiap mahasiswa, umumkan hasil kuis dan berikan reward.

n) GI (Group Investigation). Model koperatif tipe GI denganp engarahan, buat kelompok heterogen dengan orientasi tugas, 
INTIQAD: JURNAL AGAMA DAN PENDIDIKAN ISLAM

ISSN 1979-9950 (print) || ISSN 2598-0033 (online), http://jurnal.umsu.ac.id/index.php/intiqad

DOI: $10.30596 /$ intiqad.v\%vi\%i.3753

Vol. 11, No. 2 (Desember 2019)

rencanakan pelaksanaan

investigasi, tiap kelompok menginvestigasi proyek tertentu (bisa di luar kelas, misal mengukur tinggi pohon, mendata banyak dan jenis kendaraan di dalam kampus, jenis dagangan dan keuntungan di kantin kampus, banyak dosen dan staf di fakultas), pengolahan data penyajian data hasil investigasi, presentasi, kuis individual, buat skor perkembangan mahasiswa, umumkan hasil kuis dan berikan reward.

o) MEA (Means-Ends Analysis) Model pembelajaran ini adalah variasi dari pembelajaran dengan pemecahan masalah dengan cara sajikan materi dengan pendekatan pemecahan masalah berbasis heuristic, elaborasi menjadi subsub masalah yang lebih sederhana, identifikasi perbedaan, susun sub-sub masalah sehingga terjadi koneksivitas, pilih strategi solusi.

p) CPS (Creative Problem Solving). Model ini juga merupakan variasi dari pembelajaran dengan pemecahan masalah melalui teknik sistematik dalam mengorganisasikan gagasan kreatif untuk menyelesaikan suatu permasalahan. Caranya adalah mulai dari fakta aktual sesuai dengan materi bahan ajar melalui tanya jawab lisan, identifikasi permasalahan dan fokus-pilih, mengolah pikiran sehingga muncul gagasan orisinil untuk menentukan solusi, presentasi dan diskusi.

q) TS-TS (Two Stay - Two Stray). TS-TS adalah dengan cara mahasiswa berbagi pengetahuan dan pengalaman dengan kelompok lain. Arahannya adalah kerja kelompok, dua mahasiswa bertamu ke kelompok lain dan dua mahasiswa lainnya tetap di kelompoknya untuk menerima dua orang dari kelompok lain, kerja kelompok, kembali ke kelompok asal, kerja kelompok, laporan kelompok.

\section{Pengelolaan Proses Pembelajaran}

Dosen memiliki tanggung jawab penuh atas pengelolaan proses pembelajaran. Adapun yang menjadi 
ISSN 1979-9950 (print) || ISSN 2598-0033 (online), http://jurnal.umsu.ac.id/index.php/intiqad

DOI: $10.30596 /$ intiqad.v\%vi\%i.3753

Vol. 11, No. 2 (Desember 2019)

fokus sasarannya adalah unsur-unsur dari proses pembelajaran dan menjadikan seefektif mungkin dan seoptimal mungkin unsur-unsur tersebut. Agar keadaan ini dapat terlaksana sesuai dengan yang diharapkan, maka ada dua kegiatan pokok yang harus dilaksanakan oleh para dosen, yaitu:

a) Mempersiapkan diri dan unsurunsur lainnya yang akan dilibatkan dalam proses pembelajaran.

b) Mengoperasikan hal-hal yang sudah dipersiapkan dengan memperhatikan variasi dan pengembangan seperlunya, utamanya perhatian terhadap metode pembelajaran.

Atas dasar pemikiran tersebut, maka pada bagian ini pengelolaan proses pembelajaran akan ditinjau dari dua pendekatan, yaitu pendekatan konseptual dan pendekatan operasional. Dua pendekatan ini sebenarnya saling berhubungan dalam rangka pencapaian tujuan pembelajaran secara optimal.

\section{Bentuk-bentuk Komunikasi Dalam}

\section{Proses Pembelajaran}

$$
\begin{gathered}
\text { Ada tiga bentuk komunikasi } \\
\text { yang dapat digunakan untuk }
\end{gathered}
$$

mengembangkan interaski dinamis antara dosen dan mahasiswa. Ketiga pola komunikasi tersebut adalah:

a. Komunikasi sebagai aksi atau komunikasi satu arah. komunikasi jenis ini, Dosen berperan sebagai pemberi aksi dan mahasiswa sebagai penerima aksi. Komunikasi dalam bentuk ini identik dengan menggunakan metode ceramah. Metode ceramah pada dasarnya merupakan komunikasi satu arah atau komunikasi sebagai aksi. Komunikasi jenis ini tidak banyak menghidupkan suasana belajar mahasiswa. Pemahaman tentang komunikasi searah disebut sebagai "defenisi berorientasi-sumber".

b. Komunikasi sebagai interaksi atau komunikasi dua arah. Pada komunikasi jenis ini dosen dan mahasiswa dapat berperan secara bersama-sama yakni pemberi aksi dan penerima aksi. Dosen dan mahasiswa dapat saling memberi dan menerima. Komunikasi ini lebih baik dari komunikasi yang pertama, karena kegiatan dosen dan mahasiswa relatif sama.. 
ISSN 1979-9950 (print) || ISSN 2598-0033 (online), http://jurnal.umsu.ac.id/index.php/intiqad

DOI: $10.30596 /$ intiqad.v\%vi\%i.3753

Vol. 11, No. 2 (Desember 2019)

c. Komunikasi sebagai transaksi atau komunikasi banyak arah. Komunikasi ini tidak hanya melibatkan interaksi dinamis antara dosen dan mahasiswa, tetapi juga melibatkan interaksi dinamis antara mahasiswa yang satu dengan mahasiswa yang lainnya. Proses belajar di kelas dengan menggunakan pola ini mengarah pada pembelajaran yang mengembangkan kegiatan mahasiswa secara optimal, sehingga mampu menumbuhkan aktivitas belajar dan kreativitas mahasiswa. ${ }^{8}$

\section{Faktor-Faktor}

Penghambat

\section{Dalam Proses Pembelajaran.}

Banyak faktor yang dapat menyebabkan terjadi gangguan komunikasi (noise) dalam proses belajar di kelas, yaitu dosen, proses belajarnya dan mahasiswa.

\section{a. Gangguan Komunikasi yang bersumber dari Dosen}

${ }^{8}$ Pace, R. Wayne dan Don f. Faules. Komunikasi Organisasi; Strategi Meningkatkan Kinerja Perusahaan.(edt. Deddy Mulyana). (Bandung : Rosda Karya. 1998), h.61-66
Ada dua hal yang memungkinkan terjadinya gangguan komunikasi, yang berasal dari Dosen :

1) Kepribadian Dosen.

Aspek ini merupakan salah satu bagian yang memerlukan perhatian dalam rangka menjadikan proses belajar menjadi berdaya guna dan berhasil guna. Kepribadian memberi pengaruh terhadap pola kepemimpinan yang diterapkan oleh dosen ketika melaksanakan tugas pembelajaran. Sikap dosen yang otoriter menyebabkan tidak terjadi komunikasi efektif karena kegiatan dosen lebih dominan dari mahasiswa, dosen unjuk diri sebagai satu-satunya sumber belajar yang ada, dosen bersifat reseptif, menerima dan mencatat.

\section{2) Kemampuan Dosen.}

Setiap lulusan kuliah yang bertujuan untuk mengambil profesi sebagai dosen memiliki kualifikasi untuk melaksanakan tugas sebagai 
INTIQAD: JURNAL AGAMA DAN PENDIDIKAN ISLAM

ISSN 1979-9950 (print) || ISSN 2598-0033 (online), http://jurnal.umsu.ac.id/index.php/intiqad

DOI: $10.30596 /$ intiqad.v\%vi\%i.3753

Vol. 11, No. 2 (Desember 2019)

pendidik di lembaga

pendidikan, karena ia telah

memiliki seperangkat

kemampuan tertentu. Setiap

kemampuan dicapai melalui

sejumlah pengalaman belajar

yang sesuai. Kemampuan dan

pengalaman belajar tersebut

disebut dengan kompetensi

ke-dosenan, yang telah

dibakukan oleh Departemen

Pendidikan Nasional. Adapun

kompetensi yang dimaksud

adalah:

a) Penguasaan bahan

pelajaran beserta konsep-

konsep dasar

keilmuannya.

b) Pengelolaan program

belajar - mengajar

c) Pengelolaan kelas

d) Penggunaan media dan sumber pembelajaran

e) Penguasaan landasan landasan kependidikan

f) Pengelolaan interaksi pembelajaran

g) Penilaian prestasi

mahasiswa h) Pengenalan fungsi dan program bimbingan dan penyuluhan

i) Pengenalan dan penyelenggaraan

administrasi sekolah

j) Pemahaman prinsip prinsip dan pemanfaatan hasil penelitian pendidikan untuk kepentingan peningkatan mutu pengajaran.

Idealnya, sepuluh unsur kemampuan tersebut dimiliki oleh seorang Dosen, namun kenyataannya belumlah demikian.

b. Gangguan komunikasi yang bersumber pada proses Pembelajaran

Proses pembelajaran merupakan titik temu dari dua jenis kegiatan yaitu kegiatan membelajarkan yang melibatkan peran Dosen dan kegiatan belajar yang melibatkan kegiatan mahasiswa. Kedua jenis kegiatan ini berlangsung serentak dan terpadu yang melibatkan 
INTIQAD: JURNAL AGAMA DAN PENDIDIKAN ISLAM

ISSN 1979-9950 (print) || ISSN 2598-0033 (online), http://jurnal.umsu.ac.id/index.php/intiqad

DOI: $10.30596 /$ intiqad.v\%vi\%i.3753

Vol. 11, No. 2 (Desember 2019)

sejumlah individu dalam situasi kebersaman.

Komunikasi sebagai salah

satu fenomena kebersamaan

dalam proses pembelajaran

(sistem klasik) sangat esensial

untuk pencapaian tujuan

pembelajaran. Bagaimana cara

menciptakan, memelihara dan

meningkatkan komunikasi yang

efektif dalam proses belajar,

dipulangkan pada peranan Dosen

dalam mengelola proses belajar

di kelas.

Selain latar belakang pendidikan dan pengalaman untuk melaksanakan tanggung jawab profesional, peranan Dosen sebagai motivator dan insiator menjadi prasayarat untuk dapat mengelola proses belajar secara optimal. Dengan kata lain, bahwa untuk menjaga agar komunikasi dalam proses belajar tidak terpecah, inisiatif Dosen dalam menata unsur-unsur pembelajaran sangat menentukan.

c. Gangguan Komunikasi yang bersumber pada mahasiswa.

Mahasiswa

yang

mengikuti proses belajar memiliki kondisi yang berbedabeda. Kondisi mahasiswa yang homogen jika diamati secara cermat akan kelihatan heterogenitasnya. Kondisi mahasiswa dapat dibedakan atas dua kategori utama yaitu fisik dan Psikis. Setap mahasiswa pasti berbeda-beda dalam hal kekuatan fisiknya, daya tahan tubuh dan kesegaran tubuhnya. Begitu juga dengan kondisi psikologisnya, mereka berbeda dalam hal intelegensi, bakat, motif berprestasi, kematangan, aspirasi dan harapan serta ambisi pribadi.

d. Gangguan Komunikasi yang bersumber pada lingkungan Pembelajaran

Manusia dan lingkungan adalah dua aspek yang tidak terpisahkan. Manusia berkembang melalui lingkungan tempat ia hidup. Lingkungan memberi makna pada kehidupan manusia. Manusia memiliki sejumlah kemampuan yang dapat dikembangkan melalui 
ISSN 1979-9950 (print) || ISSN 2598-0033 (online), http://jurnal.umsu.ac.id/index.php/intiqad

DOI: $10.30596 /$ intiqad.v\%vi\%i.3753

Vol. 11, No. 2 (Desember 2019)

pengalaman. Pengalaman itu terjadi karena manusia berhubungan dengan lingkungannya, baik lingkungan fisik maupun lingkungan sosial secara efektif dan efesien, itulah yang disebut dengan pendidikan. Adapun tempat berlangsungnya pendidikan itu disebut lingkungan pendidikan, adapun tiga lingkungan utama pendidikan yaitu keluarga, sekolah, dan masyarakat.

B. Metode Pembelajaran Dosen AlIslam dan Kemuhammadiyahan di Universitas Muhammadiyah Sumatera Utara

1. Tingkat Pendidikan Dosen AlIslam dan Kemuhammadiyahan
Secara umum tingkat pendidikan dosen yang mengampu mata kuliah AlIslam dan Kemuhammadiyahan adalah strata 2 (S2), namun ada juga yang sudah strata 3 (S3), dan pada saat penelitian ini dilakukan bahkan ada 2 orang dosen AlIslam dan Kemuhammadiyahan masih strata $1(\mathrm{~S} 1)$.

\section{Pembahasan}

Dosen Studi Islam dan Kemuhammadiyahan yang peneliti observasi dalam penelitian ini sebanyak 14 orang.. Observasi yang peneliti lakukan berfokus pada tiga hal yaitu metode pembelajaran yang dipakai dalam pembelajaran, langkah-langkah pembelajarannya dan situasi pembelajaran yang terjadi selama proses pembelajaran berlangsung.

Tabel Hasil Observasi Metode Pembelajaran Dosen AIK

\begin{tabular}{|c|c|c|c|c|c|}
\hline No & Dosen & $\begin{array}{c}\text { Metode } \\
\text { Pembelajaran }\end{array}$ & $\begin{array}{c}\text { Langkah-Langkah } \\
\text { Pembelajaran }\end{array}$ & $\begin{array}{c}\text { Situasi } \\
\text { Pembelajaran }\end{array}$ & $\begin{array}{l}\text { Kesimpulan } \\
\text { Observator }\end{array}$ \\
\hline 1 & A & $\begin{array}{l}\text { Diskusi } \\
\text { Kelompok, } \\
\text { Tanya Jawab }\end{array}$ & $\begin{array}{l}\text { 1. Pembacaan doa } \\
\text { bersama-sama } \\
\text { 2. Absensi } \\
\text { 3. Membentuk } \\
\text { Kelompok Diskusi } \\
\text { 4.Proses } \\
\text { Pembelajaran/Diskusi } \\
\text { 5. Season Tanya Jawab }\end{array}$ & $\begin{array}{l}\text { Situasi dalam } \\
\text { Pembelajaran } \\
\text { tidak kondusif } \\
\text { karena banyak } \\
\text { mahasiswa tidak } \\
\text { memperhatikan } \\
\text { dan tidak } \\
\text { menguasai } \\
\text { materi }\end{array}$ & $\begin{array}{l}\text { Metode yang } \\
\text { dilakukan oleh } \\
\text { Dosen yang } \\
\text { bersangkutan } \\
\text { sudah baik, } \\
\text { hanya saja } \\
\text { perlu adanya } \\
\text { Stimulus dan } \\
\text { motivasi dari } \\
\text { Dosen } \\
\text { tersebut. }\end{array}$ \\
\hline
\end{tabular}


INTIQAD: JURNAL AGAMA DAN PENDIDIKAN ISLAM

ISSN 1979-9950 (print) || ISSN 2598-0033 (online), http://jurnal.umsu.ac.id/index.php/intiqad

DOI: $10.30596 /$ intiqad.v\%vi\%i.3753

Vol. 11, No. 2 (Desember 2019)

\begin{tabular}{|c|c|c|c|c|c|}
\hline & & & $\begin{array}{l}\text { 6. Kesimpulan dari } \\
\text { Dosen } \\
\text { 7. Doa Penutup }\end{array}$ & & $\begin{array}{l}\text { Sehingga } \\
\text { pembelajaran } \\
\text { akan } \\
\text { berlangsung } \\
\text { efektif dan } \\
\text { efisien. }\end{array}$ \\
\hline 2 & B & $\begin{array}{l}\text { Diskusi, } \\
\text { Presentase } \\
\text { Kelompok, } \\
\text { Tanya Jawab }\end{array}$ & $\begin{array}{l}\text { 1. Salam } \\
\text { 2. Doa } \\
\text { bersama/dipimpin } \\
\text { 3. Proses pembelajaran } \\
\text { 4. Diskusi/Tanya jawab } \\
\text { 5. Penguatan materi } \\
\text { 6. Pesan dan nasehat } \\
\text { 7. Penutup } \\
\text { 8. Absen } \\
\text { 9. Doa/salam }\end{array}$ & $\begin{array}{l}\text { Situasi dalam } \\
\text { pembelajaran } \\
\text { Alhamdulillah } \\
\text { tenang dan } \\
\text { kondusif } \\
\text { apabila tidak } \\
\text { kondusif, proses } \\
\text { pembelajaran } \\
\text { tidak akan } \\
\text { dimulai }\end{array}$ & $\begin{array}{l}\text { Metode serta } \\
\text { langkah- } \\
\text { langkah yang } \\
\text { dipakai sudah } \\
\text { memenuhi } \\
\text { standar dalam } \\
\text { kompetensi } \\
\text { pembalajaran. } \\
\text { Sehingga } \\
\text { proses } \\
\text { pembelajaran } \\
\text { dapat } \\
\text { berlangsung } \\
\text { dengan baik } \\
\text { dan } \\
\text { efektif/efisien }\end{array}$ \\
\hline 3 & $\mathrm{C}$ & $\begin{array}{l}\text { Diskusi,Tanya } \\
\text { Jawab, Sorogan } \\
\text { (hafal surah) }\end{array}$ & $\begin{array}{l}\text { 1. Salam } \\
\text { 2. Doa dipimpin oleh } \\
\text { Relator } \\
\text { 3. Proses pembelajaran } \\
\text { (hafalan surah) } \\
\text { 4. } \\
\text { 5. Absen } \\
\text { 6. Penutup Materi } \\
\text { 7. Doa yang dipimpim } \\
\text { oleh Relator Relator } \\
\text { 8. Salam }\end{array}$ & $\begin{array}{l}\text { Setelah diamati, } \\
\text { bahwa situasi } \\
\text { pembelajaran } \\
\text { Tidak Kondusif, } \\
\text { disebabkan } \\
\text { dosen yang } \\
\text { tidak peduli } \\
\text { dengan situasi } \\
\text { pembelajaran. }\end{array}$ & $\begin{array}{l}\text { Metode yang } \\
\text { dipakai sudah } \\
\text { cukup bagus, } \\
\text { hanya saja, } \\
\text { dosen } \\
\text { sebaiknya lebih } \\
\text { perhatian } \\
\text { kepada } \\
\text { mahasiswa, } \\
\text { supaya situasi } \\
\text { pembelajaran } \\
\text { menjadi efektif } \\
\text { /efisien. }\end{array}$ \\
\hline 4 & $\mathrm{D}$ & $\begin{array}{l}\text { Diskusi, Tanya } \\
\text { Jawab }\end{array}$ & $\begin{array}{l}\text { 1.Salam } \\
\text { 2.Doa } \\
\text { 3.Proses } \\
\text { pembelajarannya } \\
\text { 3.Diskusi } \\
\text { 4.Tanya Jawab } \\
\text { 5.Selesai } \\
\text { 6.Absensi } \\
\text { 7.Salam }\end{array}$ & $\begin{array}{l}\text { Situasi } \\
\text { pembelajaran } \\
\text { tenang dan } \\
\text { kondusif, hanya } \\
\text { saja mahasiswa } \\
\text { pasif dalam } \\
\text { bertanya }\end{array}$ & $\begin{array}{l}\text { kurang } \\
\text { menyenangkan } \\
\text { mahasiswa ada } \\
\text { yang } \\
\text { mengeluh. }\end{array}$ \\
\hline
\end{tabular}


INTIQAD: JURNAL AGAMA DAN PENDIDIKAN ISLAM

ISSN 1979-9950 (print) || ISSN 2598-0033 (online), http://jurnal.umsu.ac.id/index.php/intiqad

DOI: $10.30596 /$ intiqad.v\%vi\%i.3753

Vol. 11, No. 2 (Desember 2019)

\begin{tabular}{|c|c|c|c|c|c|}
\hline 5 & $\mathrm{E}$ & $\begin{array}{l}\text { Ceramah, Tanya } \\
\text { Jawab }\end{array}$ & $\begin{array}{l}\text { 1. Kelas dimulai } \\
\text { dengan salam } \\
\text { kemudian berdoa } \\
\text { masing-masing yang } \\
\text { dipimpin dosen } \\
\text { 2. Dosen menuliskan } \\
\text { materi muamalah di } \\
\text { papan tulis, sambil } \\
\text { menjelaskan } \\
\text { 3. Dosen membuka } \\
\text { wacana berpikir dan } \\
\text { merespon pertanyaan } \\
\text { dan sanggahan yang } \\
\text { muncul dengan } \\
\text { memberikan solusi } \\
\text { 4. Dosen dengan } \\
\text { menyimpulkan } \\
\text { materi kemudian } \\
\text { mengundang } \\
\text { mahasiswa untuk } \\
\text { bertanya } \\
\text { 5. Dosen mengabsen } \\
\text { kehadiran mahasiswa } \\
\text { 6. Ditutup den } \\
\text { salam }\end{array}$ & $\begin{array}{l}\text { Kondusif, } \\
\text { namun } \\
\text { sebagian } \\
\text { mahasiswa yang } \\
\text { mengobrol, } \\
\text { makan, main, dll }\end{array}$ & $\begin{array}{l}\text { Dosen bisa } \\
\text { menguasai } \\
\text { kelas dan } \\
\text { menyampaika } \\
\text { n substansi } \\
\text { materi kepada } \\
\text { mahasiswa }\end{array}$ \\
\hline 6 & $\mathrm{~F}$ & $\begin{array}{l}\text { Diskusi } \\
\text { kelompok,Tanya } \\
\text { jawab }\end{array}$ & $\begin{array}{l}\text { 1. Kelas dimulai } \\
\text { dengan salam. } \\
\text { 2. Dilanjutkan dengan } \\
\text { diskusi kelompok } \\
\text { 3. Kelompok pemateri, } \\
\text { memaparkan materi } \\
\text { dan dibuka Tanya } \\
\text { jawab } \\
\text { 4. Dosen mendampingi } \\
\text { setiap pertanyaan } \\
\text { dengan solusi } \\
\text { 5. Dosen mengajak } \\
\text { membuka wacana } \\
\text { berpikir mahasiswa } \\
\text { 6. Dosen membuat } \\
\text { kesimpulan/ } \\
\text { penekanan } \\
\text { 7. Absensi kehadiran } \\
\text { 8. Doa penutup } \\
\text { 9. Salam }\end{array}$ & $\begin{array}{l}\text { Kondusif, } \\
\text { mahasiswa } \\
\text { mengikuti } \\
\text { materi dengan } \\
\text { antausias } \\
\text { walaupun } \\
\text { sebagian sambil } \\
\text { main hp }\end{array}$ & $\begin{array}{l}\text { dosen mampu } \\
\text { mengendalika } \\
\text { n kelas dan } \\
\text { metode yang } \\
\text { digunakan } \\
\text { juga baik, } \\
\text { substansi } \\
\text { materi } \\
\text { tercapai }\end{array}$ \\
\hline 7 & $\mathrm{G}$ & $\begin{array}{l}\text { Presentase } \\
\text { Kelompok, } \\
\text { Tanya Jawab, } \\
\text { Ceramah }\end{array}$ & $\begin{array}{l}\text { 1. Membaca doa } \\
\text { 2. Persentasi masing- } \\
\text { masing kelompok } \\
\text { 3. Tanya jawab } \\
\text { 4. Penjelasan atau }\end{array}$ & $\begin{array}{l}\text { Tidak Kondusif } \\
\text { karena } \\
\text { 1. Banyak } \\
\text { mahasiswa }\end{array}$ & $\begin{array}{l}\text { Pembelajaran } \\
\text { belum efektif, } \\
\text { karena } \\
\text { sebagian }\end{array}$ \\
\hline
\end{tabular}


INTIQAD: JURNAL AGAMA DAN PENDIDIKAN ISLAM

ISSN 1979-9950 (print) || ISSN 2598-0033 (online), http://jurnal.umsu.ac.id/index.php/intiqad

DOI: $10.30596 /$ intiqad.v\%vi\%i.3753

Vol. 11, No. 2 (Desember 2019)

\begin{tabular}{|c|c|c|c|c|c|}
\hline & & & $\begin{array}{l}\text { tambahan materi oleh } \\
\text { dosen, absensi } \\
\text { 5. Diskusi dosen } \\
\text { dengan mahasiswa } \\
\text { tentang materi. } \\
\text { 6. Membaca doa } \\
\text { penutup majelis } \\
\text { 7. Mengumpulkan tugas } \\
\text { yang diberikan dosen } \\
\text { pada materi } \\
\text { sebelumnya }\end{array}$ & $\begin{array}{l}\text { yang } \\
\text { terlambat } \\
\text { masuk } \\
\text { 2. Sebagian } \\
\text { mahasiswa } \\
\text { ada yang } \\
\text { cerita dengan } \\
\text { teman yang } \\
\text { lain, dan main } \\
\text { hp, dll } \\
\text { 3. Beberapa } \\
\text { mahasiswa } \\
\text { mengerjakan } \\
\text { tugas saat } \\
\text { diskusi } \\
\text { kelompok } \\
\end{array}$ & $\begin{array}{l}\text { mahasiswa } \\
\text { tidak } \\
\text { mendengarkan } \\
\text { materi yang } \\
\text { disampaikan } \\
\text { oleh kelompok } \\
\text { yang } \\
\text { presentase dan } \\
\text { dosen. }\end{array}$ \\
\hline 8 & $\mathrm{H}$ & $\begin{array}{l}\text { Ceramah, Tugas } \\
\text { Individu }\end{array}$ & $\begin{array}{l}\text { 1. Mengucapkan salam } \\
\text { 2. Penyampaian materi } \\
\text { 3. Absensi } \\
\text { 4. Pengumpulan tugas } \\
\text { individu } \\
\text { 5. Penutup }\end{array}$ & $\begin{array}{l}\text { Tidak efektif } \\
\text { karena } \\
\text { a.sebagian } \\
\text { mahasiswa } \\
\text { cerita, main HP, } \\
\text { tidur, dll } \\
\text { b.Mahasiswa } \\
\text { banyak } \\
\text { terlambat masuk }\end{array}$ & $\begin{array}{l}\text { Pembelajaran } \\
\text { kurang } \\
\text { berjalan } \\
\text { dengan baik, } \\
\text { karena banyak } \\
\text { mahasiswa } \\
\text { tidak } \\
\text { memperhatika } \\
\text { n materi yang } \\
\text { disampaikan } \\
\text { oleh dosen. }\end{array}$ \\
\hline 9 & I & $\begin{array}{l}\text { Metode ceramah } \\
\text { Demonstrasi } \\
\text { materi }\end{array}$ & $\begin{array}{l}\text { 1. Salam pembuka } \\
\text { 2. Doa belajar } \\
\text { 3. Dosen mengabsen } \\
\text { mahasiswa } \\
\text { 4. Dosen } \\
\text { menyampaikan } \\
\text { materi dengan } \\
\text { ceramah dan } \\
\text { sekaligus } \\
\text { menampilkan slide } \\
\text { materi perkuliahan } \\
\text { 5. Mahasiswa diminta } \\
\text { menceritakan } \\
\text { kembali penjelasan } \\
\text { dosen } \\
\text { 6. Salam penutup }\end{array}$ & $\begin{array}{l}\text { Situasi belajar } \\
\text { mengajar } \\
\text { terlihat kurang } \\
\text { aktif karena } \\
\text { dosen hanya } \\
\text { fokus } \\
\text { menjelaskan } \\
\text { materi yang } \\
\text { telah disusun di } \\
\text { slide }\end{array}$ & $\begin{array}{l}\text { 1. Metode } \\
\text { ceramah } \\
\text { kurang } \\
\text { efektif } \\
\text { digunakan } \\
\text { karena } \\
\text { keaktifan } \\
\text { mahasiswa } \\
\text { menjadi } \\
\text { terbatas } \\
\text { 2.Dosen harus } \\
\text { lebih kreatif } \\
\text { dalam } \\
\text { perkuliahan } \\
\text { sehingga } \\
\text { menstimulus } \\
\text { mahasiswa } \\
\text { untuk aktif. }\end{array}$ \\
\hline 10 & $\mathrm{~J}$ & $\begin{array}{l}\text { Diskusi } \\
\text { kelompok dan }\end{array}$ & $\begin{array}{l}\text { 1. Pembukaan oleh } \\
\text { dosen pembimbing } \\
\text { sekaligus pembacaan }\end{array}$ & $\begin{array}{l}\text { Kelas terlihat } \\
\text { lebih aktif dan }\end{array}$ & $\begin{array}{l}\text { Metode } \\
\text { diskusi lebih }\end{array}$ \\
\hline
\end{tabular}


INTIQAD: JURNAL AGAMA DAN PENDIDIKAN ISLAM

ISSN 1979-9950 (print) || ISSN 2598-0033 (online), http://jurnal.umsu.ac.id/index.php/intiqad

DOI: $10.30596 /$ intiqad.v\%vi\%i.3753

Vol. 11, No. 2 (Desember 2019)

\begin{tabular}{|c|c|c|c|c|c|}
\hline & & ceramah & $\begin{array}{l}\text { doa belajar } \\
\text { 2. Kelompok yang } \\
\text { bertugas sebagai } \\
\text { pemateri mengambil } \\
\text { posisi di depan kelas } \\
\text { 3. Kelompok/ } \\
\text { pemakalah } \\
\text { membacakan materi } \\
\text { 4. Dosen membimbing } \\
\text { serta mahasiswa lain } \\
\text { memberi pertanyaan } \\
\text { (sesi Tanya jawab) } \\
\text { 5. Dosen } \\
\text { menyimpulkan isi } \\
\text { makalah } \\
\text { 6. Penutup }\end{array}$ & $\begin{array}{l}\text { mahasiswa } \\
\text { memiliki } \\
\text { kesempatan } \\
\text { untuk } \\
\text { mengungkapkan } \\
\text { pendapat }\end{array}$ & $\begin{array}{l}\text { efektif } \\
\text { digunakan } \\
\text { untuk tingkat } \\
\text { mahasiswa, } \\
\text { karena dengan } \\
\text { itu melatih } \\
\text { agar } \\
\text { mahasiswa } \\
\text { memiliki } \\
\text { keberanian } \\
\text { berbicara dan } \\
\text { mengungkapk } \\
\text { an pendapat } \\
\text { serta mau } \\
\text { bertanya }\end{array}$ \\
\hline 11 & $\mathrm{~K}$ & $\begin{array}{l}\text { Persentase } \\
\text { kelompok, } \\
\text { Tanya jawab }\end{array}$ & $\begin{array}{l}\text { 1. Mengucap salam } \\
\text { 2. Membaca doa } \\
\text { 3. Penyampaian materi } \\
\text { yang dipersentasekan } \\
\text { oleh setiap kelompok } \\
\text { 4. Tanya jawab } \\
\text { 5. Penyampaian materi } \\
\text { oleh dosen } \\
\text { 6. Penutup } \\
\text { 7. Doa }\end{array}$ & $\begin{array}{l}\text { Mahasiswa } \\
\text { bermain hp, } \\
\text { notebook, dll } \\
\text { Sebagian } \\
\text { mahasiswa ribut } \\
\text { dengan teman } \\
\text { yang lain }\end{array}$ & $\begin{array}{l}\text { Pembelajaran } \\
\text { yang } \\
\text { dilaksanakan } \\
\text { tidak efektif, } \\
\text { karena banyak } \\
\text { sekali } \\
\text { mahasiswa } \\
\text { yang tidak } \\
\text { mendengarkan } \\
\text { materi yang } \\
\text { disampaikan } \\
\text { oleh dosen } \\
\text { maupun setiap } \\
\text { kelompok. }\end{array}$ \\
\hline 12 & $\mathrm{~L}$ & $\begin{array}{l}\text { Soal kuis, } \\
\text { menjawab } \\
\text { pertanyaan }\end{array}$ & $\begin{array}{l}\text { 1. Mengucap salam } \\
\text { 2. Membaca doa } \\
\text { 3. Soal kuis di selembar } \\
\text { kertas } \\
\text { 4. Dikerjakan dan } \\
\text { dikumpul } \\
\text { 5. Absensi } \\
\text { 6. Setiap mahasiswa } \\
\text { yang sudah selesai } \\
\text { menjawab soal kuis } \\
\text { langsung pulang }\end{array}$ & $\begin{array}{l}\text { Tidak kondusif } \\
\text { karena beberapa } \\
\text { mahasiswa rebut } \\
\text { dan } \\
\text { ada sebagian } \\
\text { mahasiswa } \\
\text { bermain } \mathrm{Hp} \text {. }\end{array}$ & $\begin{array}{l}\text { Pembelajaran } \\
\text { untuk } \\
\text { menjawab soal } \\
\text { tidak berjalan } \\
\text { dengan baik, } \\
\text { karena ketika } \\
\text { mahasiswa } \\
\text { menjawab soal } \\
\text { tidak diawasi } \\
\text { oleh dosen. }\end{array}$ \\
\hline 13 & M & $\begin{array}{l}\text { Ceramah dengan } \\
\text { menampilkan }\end{array}$ & $\begin{array}{l}\text { 1. Kelas dibuka dengan } \\
\text { salam dan berdoa } \\
\text { 2. Dosen mengabsen }\end{array}$ & $\begin{array}{l}\text { Cukup kondusif } \\
\text { namun sebagian } \\
\text { mahasiswa ada }\end{array}$ & $\begin{array}{ll}\text { Dosen } & \text { terkait } \\
\text { mampu } & \text { dalam } \\
\text { mata } & \text { kuliah }\end{array}$ \\
\hline
\end{tabular}




\begin{tabular}{|c|c|c|c|c|c|}
\hline \multicolumn{6}{|c|}{$\begin{array}{l}\text { INTIQAD: JURNAL AGAMA DAN PENDIDIKAN ISLAM } \\
\text { ISSN 1979-9950 (print) || ISSN 2598-0033 (online), http://jurnal.umsu.ac.id/index.php/intiqad } \\
\text { DOI: 10.30596/intiqad.v\%vi\%i.3753 } \\
\text { Vol. 11, No. } 2 \text { (Desember 2019) }\end{array}$} \\
\hline & & $\begin{array}{l}\text { slide bahan ajar, } \\
\text { Diskusi (Tanya } \\
\text { jawab) }\end{array}$ & 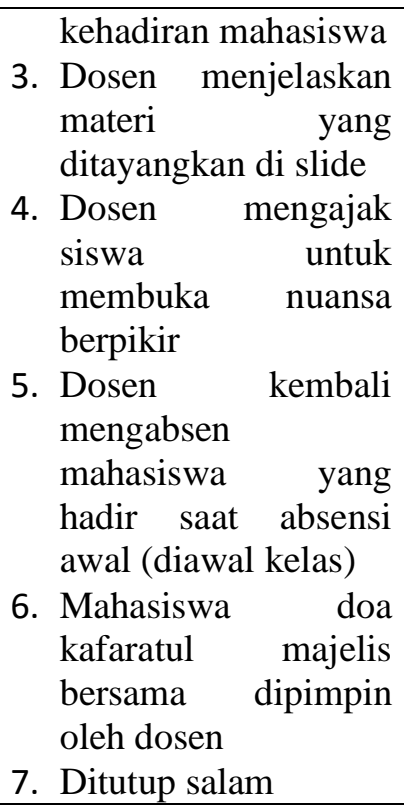 & $\begin{array}{l}\text { yang terlambat } \\
\text { masuk }\end{array}$ & $\begin{array}{l}\text { studi islam dan } \\
\text { substansi } \\
\text { pelajaran } \\
\text { berhasil } \\
\text { dicapai }\end{array}$ \\
\hline 14 & $\mathrm{~N}$ & $\begin{array}{l}\text { Ceramah } \\
\text { (bermedia } \\
\text { infokus), } \\
\text { Diskusi }\end{array}$ & $\begin{array}{l}\text { 1. kelas dibuka dengan } \\
\text { salam } \\
\text { 2. dosen mengabsen } \\
\text { mahasiswa (cek } \\
\text { kehadiran) } \\
\text { 3. dosen menjelaskan } \\
\text { materi dengan detail } \\
\text { tiap slide yang } \\
\text { ditayangkan } \\
\text { 4. dosen berinteraksi } \\
\text { dengan mahasiswa } \\
\text { tentang aplikasi } \\
\text { (penerapan) materi } \\
\text { dengan realita } \\
\text { kehidupan dengan } \\
\text { bertanya tentang } \\
\text { kejujuran mahasiswa } \\
\text { sholat atau tidak } \\
\text { 5. seluruh mahasiswa } \\
\text { berdoa kafaratul } \\
\text { majelis bersama- } \\
\text { samarararanas dosen } \\
\text { mengucapkan salam }\end{array}$ & $\begin{array}{l}\text { Cukup kondusif, } \\
\text { namun sebagian } \\
\text { ada yang tidak } \\
\text { serius dengan } \\
\text { bermain Hp, } \\
\text { bercerita dengan } \\
\text { teman }\end{array}$ & $\begin{array}{l}\text { Dosen terkait, } \\
\text { mempunyai } \\
\text { kredibilitas } \\
\text { dalam } \\
\text { menyampaika } \\
\mathrm{n} \text { mata kuliah } \\
\text { studi islam, } \\
\text { menarik } \\
\text { perhatian } \\
\text { (mahasiswa) } \\
\text { dalam } \\
\text { menyampaika } \\
\mathrm{n} \text { dalil-dalil } \\
\text { yang sohih. }\end{array}$ \\
\hline
\end{tabular}

Metode Pembelajaran Dosen Al-Islam dan Kemuhammadiyahan

Ditemukan beberapa metode pembelajaran yang diperaktekkan oleh dosen-dosen mata kuliah AIK di
Universitas Muhammadiyah Sumatera Utara dalam memberi perkuliahan. Dari kesemua metode yang ditemukan itu dapat dikelompokkan menjadi tiga katagori yaitu metode klasik, 
INTIQAD: JURNAL AGAMA DAN PENDIDIKAN ISLAM

ISSN 1979-9950 (print) || ISSN 2598-0033 (online), http://jurnal.umsu.ac.id/index.php/intiqad

DOI: $10.30596 /$ intiqad.v\%vi\%i.3753

Vol. 11, No. 2 (Desember 2019)

pertengahan dan modern. Berikut ini akan dipaparkan satu persatu.

\section{Metode Klasik}

Metode pembelajaran klasik yang dimaksudkan adalah pembelajaran yang ada dari zaman dahulu. Ditemukan praktek dosendosen AIK adalah metode ceramah. Metode ceramah termasuk dalam metode klasik karena memang dalam metode ceramah yang aktif hanya dosen. Sedangkan mahasiswa hanya pasif (mendengar) informasi yang diberikan oleh Dosen.

Proses pembelajaran yang dilakukan dengan menggunakan metode klasik ini terkesan monoton karena dari awal sampai akhir proses pembelajaran hanya menggunakan metode ceramah. Komunikasi pembelajaran yang terjadi terlihat hanya satu arah. Kondisi kelas tidak efektif, hanya sedikit mahasiswa yang memperhatikan materi yang disampaikan oleh dosen, mahasiswa sibuk dengan aktivitasnya masingmasing. Bahkan ada yang ngobrol, main hp (sms, bbm dan browsing), ada juga yang sambil mengerjakan tugas dari dosen.

\section{Metode Pertengahan}

Metode pertengahan adalah metode pembelajaran yang berada diantara klasik dan modern. Perbedaan antara keduanya adalah bahwa metode tengahan ini diberi kesempatan atau peluang tanya jawab bagi mahasiswa dalam proses pembelajaran. Dengan metode ini fenomena pembelajaran yang mengalir lebih aktif dibandingkan dengan metode klasik. Namun agar muncul feedback dari mahasiswa, dosen harus bisa merangsang mahasiswa saat menyampaikan materi kuliah pada saat aktivitas perkuliahan agar mahasiswa termotivasi dalam mengikuti dan ambil bagian dari perkuliahan. Keaktifan dosen sangat berpengaruh kepada keaktifan mahasiswa, dosen harus mampu mengemas dengan baik dan menarik sehingga muncul pertanyaan dari mahasiswa.

\section{Metode Modern}

Metode moderen adalah metode pembelajaran yang mengarahkan dan menuntut keaktifan mahasiswa dalam proses perkuliahan. Hal ini menunjukkan paradigma bahwa belajar adalah mahasiswa. Dosen hanya sebagai fasilitator dalam 
INTIQAD: JURNAL AGAMA DAN PENDIDIKAN ISLAM

ISSN 1979-9950 (print) || ISSN 2598-0033 (online), http://jurnal.umsu.ac.id/index.php/intiqad

DOI: $10.30596 /$ intiqad.v\%vi\%i.3753

Vol. 11, No. 2 (Desember 2019)

proses perkuliahan berlangsung.

Adapun metode yang tergolong ke dalam ini adalah metode diskusi.

Diskusi yang dilakukan dan proses perkuliahan mahasiswa lebih aktif dosen hanya sebagai fasilitator. Mahasiswa dengan mahasiswa, mahasiswa dengan dosen memiliki transaksi komunikasi yang lebih aktif. Bahkan dosen hanya akan sebagai fasilitator dan mengarahkan, sebagai pemantau sekaligus memberikan kata-kata kunci terhadap materi yang menjadi tema pada saat itu, hal inipun jika mahasiswa belum mampu sepenuhnya memahami materi perkuliahan.

\section{Kesimpulan}

1. Metode pembelajaran dalam perkuliahan yang diterapkan oleh dosen AIKdi Universitas Muhammadiyah Sumatera Utara tergolong bervariasi, misalnya ceramah, pemberian tugas individu, tanya jawab dan diskusi. Pada saat observasi penelitian ini dilakukan belum ada dosen AIK menggunakan metode praktek dalam pembelajaran.
2. Langkah-langkah pembelajaran dalam perkuliahan yang dilakukan oleh Dosen AIK sudah menerapkan manajemen kelas Islami seperti memulai dengan salam, membaca doa diawal dan diakhir perkuliahan, hanya saja pembelajaran yang dilakukan belum menarik dan menyenangkan karena terkesan monoton.

3. Situasi perkuliahan di dalam kelas belum sepenuhnya kondusif karena sebagian dosen AIK tidak bisa menguasai kelas, sehingga ada juga mahasiswa yang ngobrol dan bermain hp.

Dalam rangka peningkatan kualitas pembelajaran dalam perkuliahan di Universitas Muhammadiyah Sumatera Utara khususnya mata kuliah AIK, maka disarankan kiranya dosen AIK harus meningkatkan pengayaan metode pembelajaran dalam perkuliahan, bisa dalam bentuk pelatihan. Begitu juga dalam langkah-langkah pembelajaran perlu ada ice breaking untuk memecah kejenuhan dan merefresh 
INTIQAD: JURNAL AGAMA DAN PENDIDIKAN ISLAM

ISSN 1979-9950 (print) || ISSN 2598-0033 (online), http://jurnal.umsu.ac.id/index.php/intiqad

DOI: $10.30596 /$ intiqad.v\%vi\%i.3753

Vol. 11, No. 2 (Desember 2019)

kembali mahasiswa ketika Pace, R. Wayne dan Don f. Faules.

perkuliahan berlangsung.

\section{DAFTAR PUSTAKA}

Adrian. (2006). Metodologi

Pembelajaran Efektif. Jakarta:

Bumi Aksara

Ali, Muhammad. (2007). Dosen Dalam

Proses Pembelajaran. Bandung:

Sinar Baru Algesindo.

Oemar Hamalik. (2001). Proes Belajar

Pembelajaran, Jakarta: Bumi

Aksara.

(2008).
(1998). Komunikasi Organisasi;

Strategi Meningkatkan Kinerja

Perusahaan.(edt. Deddy

Mulyana). Bandung: Rosda Karya.

Pius A. Partanto dan M. Dahlan AlBarry. (1994). Kamus Ilmiah Populer. Surabaya: Arkola.

Suharsimi Arikunto. (2008). ModelModel Metode Pembelajaran (Makalah Seminar Nasional Pendidikan) di Universitas Negeri Medan.

Pembelajaran Efektif. Jakarta: Bumi

Aksara 